\title{
PLANEJAMENTO ESTRATÉGICO COMO FERRAMENTA DE GESTÃO \\ NO INSTITUTO BRASILEIRO DE \\ GOVERNANÇA CORPORATIVA (IBGC)
}

Carine Moreira de Jesus

Fundação Instituto de Pesquisas Contábeis, Atuariais e Financeiras (Fipecafi).

Gerente administrativo financeiro da Sensenova.

E-mail: carine.jesus@fipecafi.edu.br

\section{Carlos Henrique Neris Nossa}

Fundação Instituto de Pesquisas Contábeis, Atuariais e Financeiras (Fipecafi).

Consultor sênior da PwC.

E-mail:carlos.nossa@fipecafi.edu.br

Celso Fabrini

Fundação Instituto de Pesquisas Contábeis, Atuariais e Financeiras (Fipecafi).

Consultor autônomo e microempresário.

E-mail: celso.fabrini@fipecafi.edu.br 


\section{Paschoal Tadeu Russo}

Professor doutor do Programa do Mestrado em

Controladoria e Finanças da Fundação Instituto

de Pesquisas Contábeis, Atuariais e Financeiras

(Fipecafi).

E-mail: paschoal.russo@fipecafi.org

\section{PALAVRAS-CHAVE}

Conformidade social. Planejamento estratégico. Balanced Scorecard. Ferramenta de gestão. IBGC.

\section{RESUMO}

Esta pesquisa teve como objetivo principal desenvolver e aplicar um modelo de avaliação de alinhamento de empresas valendo-se dos principais indicadores de conformidade social propostos pela EMES em cada uma das etapas do processo de planejamento estratégico. O Instituto Brasileiro de Governança Corporativa (IBGC) foi o objeto de avaliação do modelo conceitual por meio de evidências obtidas da análise de conteúdo de documentos públicos do IBGC. Os resultados sugerem que o IBGC demonstra estar alinhado com o modelo conceitual proposto, ou seja, está alinhado com os principais indicadores de conformidade social empreendedora. Foi possível localizar atividades concretas inseridas em quase $100 \%$ dos entroncamentos do modelo conceitual, além da busca de melhoria contínua em cada revisão de seu planejamento estratégico, a qual vem sendo refletida por meio de resultados positivos e em sua expansão. 


\section{INTRODUÇÃO}

Compreender o que é economia e empreendedorismo social e quais são os critérios que devem ser considerados a fim de que uma organização seja suscetível de ser denominada de "empresa social empreendedora" vem sendo objeto de estudo há algumas décadas, mas de forma mais específica desde 1996, quando um grupo internacional de pesquisadores universitários, com apoio financeiro da União Europeia, formou uma rede de pesquisa chamada EMES - International Research Network, com o objetivo de construir gradualmente um corpo de conhecimentos teóricos e empíricos sobre a economia social e o empreendedorismo social. A rede de pesquisa, que é pluralista tanto nas disciplinas envolvidas quanto nas metodologias adotadas, estuda questões relacionadas ao terceiro setor (EMES RESEARCH NETWORK, 2019).

A abordagem EMES derivou de extenso diálogo entre várias disciplinas (economia, sociologia, ciência política e gestão), bem como entre as várias tradições e sensibilidades nacionais presentes na União Europeia. Além disso, guiada por um projeto que era tanto teórico quanto empírico, desde o início, a EMES preferiu a identificação e o esclarecimento de indicadores de conformidade social empreendedora que possibilitam avaliar, de forma concisa e elegante, o alinhamento das organizações com os propósitos sociais (DEFOURNY; NYSSENS, 2008).

No Brasil, existem diversas companhias que podem merecer sua categorização como empresas sociais empreendedoras pela relevante contribuição que oferecem a toda sociedade. Entretanto, o processo que é realizado por essas organizações para a materialização das ações que as colocam em tal categoria pode não ser de amplo conhecimento, sendo assim, considera-se que evidenciar como se materializa a proposição de ser uma empresa social empreendedora pode ser uma contribuição para os que estudam a gestão das organizações e para as organizações que têm tal intento.

Nesse contexto, adota-se como questão norteadora de pesquisa:

- Como se pode avaliar o alinhamento de uma organização com os indicadores de conformidade social empreendedora propostos pela EMES?

Dessa forma, esta pesquisa tem como objetivo principal a proposição de um mo- 
delo que possibilite avaliar se uma empresa está ou não alinhada com os principais indicadores de conformidade social empreendedora.

Dentro do contexto das empresas que merecem a classificação de empresa social está o Instituto Brasileiro de Governança Corporativa (IBGC), que é a principal referência brasileira em melhores práticas de governança corporativa. Essa entidade desenvolve trabalhos de capacitação e aprofundamento em práticas de governança para empresas de diversos portes, segmentos e mercados, contribuindo para a melhoria da qualidade da gestão nessas organizações, em sua longevidade, buscando estabelecer processos de gestão tecnicamente adequados, mas, antes de tudo, eticamente estabelecidos (INSTITUTO BRASILEIRO DE GOVERNANÇA CORPORATIVA, 2019).

Para tanto, a fim de avaliar como os indicadores de conformidade social propostos pelo EMES podem evidenciar a condição de a empresa ser avaliada como social empreendedora, faz-se necessário avaliar o seu processo de gestão (planejar, executar, controlar) e verificar como tais ações são materializadas no dia a dia. Para tornar viável a realização da pesquisa, deli- mitou-se a avaliação por meio da investigação do direcionamento estratégico do IBGC no período de 1995 a 2018. Entende-se que, se as evidências contidas nos relatórios anuais dessa organização evidenciarem ações realizadas e novos caminhos a trilhar que possam ser percebidos como alinhados com os indicadores de conformidade social, tal categorização poderá ser atribuída a essa instituição, evidenciando os pontos que são referência para outras organizações e aqueles que apresentam oportunidade para melhoria.

Esta pesquisa pode ser considerada como uma pesquisa aplicada, pois ela tem por objetivo buscar formas para resolver problemas, pelo fato de propor um modelo que permite a autoavaliação de uma organização no perfil de empresa social, possibilitando que sejam percebidas oportunidades para valorização de conquistas e de evidenciação de pontos que podem ser melhorados.

Compreende-se que ferramentas dessa natureza são importantes para a constituição de empresas que de fato desejam ser empresas sociais e para a desmitificação daquelas que se intitulam como tal, mas não o são. 


\section{REFERENCIAL TEÓRICO}

\section{Empreendedorismo social e} empresas empreendedoras sociais

Schumpeter (1985, p. 49) define empreendedor como aquele que é capaz de realizar novas combinações dos meios produtivos, as quais propiciam desenvolvimento econômico, por meio da introdução de novos bens ou do modelo de produção, da abertura de novos mercados, da conquista de novas fontes de matérias-primas, constituição ou fragmentação de posicionamentos mercadológicos. Salientam-se por meio dessa definição as dimensões de inovação que geram impacto econômico.

Nesse sentido, pode-se considerar que o empreendedor seja um visionário, pois ele crê que é capaz de produzir uma mudança no contexto no qual está inserido, fugindo do padrão do tomado como certo (taken-for granted), estando, dessa forma, disposto a correr riscos. Nesse sentido, não se pode caracterizar o empreendedorismo como um atributo ligado à propriedade, nem mesmo a uma função específica, mas, sim, a um conjunto de competências que se estabelecem por meio do imbricamento de competências profissionais e tecnológicas e do contexto social em que estão inseridos, o que evidencia a importância das instituições nesse contexto (BERGER; LUCKMANN, 1998).

Dessa forma, para estudar o empreendedorismo social, faz-se necessário se valer da identificação de organizações que tenham um caráter social empreendedor, ou seja, que conseguem materializar, por meio de um conjunto de ações, aquelas que promovem a inovação e simultaneamente causam impacto econômico no contexto em que estão inseridas (DEFOURNY; NYSSENS, 2008).

Defourny e Nyssens (2008) evidenciam as dimensões econômicas e sociais das organizações sociais empreendedoras descritas pela rede de pesquisadores EMES da seguinte forma:

1) Dimensões econômica e empresarial das empresas sociais em quatro indicadores:

- atividade contínua que produz bens e/ou serviços de venda;

- alto grau de autonomia;

- nível significativo de risco econômico;

- quantidade mínima de trabalho remunerado.

2) Dimensões sociais de tais empreendimentos das empresas sociais em cinco indicadores: 
- objetivo explícito para beneficiar a comunidade;

- iniciativa lançada por um grupo de cidadãos;

- poder de decisão não baseado na propriedade do capital;

- natureza participativa, que envolve várias partes afetadas pela atividade;

- distribuição de lucros limitada.

Embora a rede de pesquisadores EMES tenha sempre trabalhado com essa lista de indicadores, não se pode deixar de considerar que as empresas sociais são organizações privadas sem fins lucrativos que fornecem bens ou serviços diretamente relacionados ao seu objetivo explícito de beneficiar. Elas geralmente dependem de uma dinâmica coletiva que envolve vários tipos de partes interessadas em seus corpos diretivos, valorizam sua autonomia e assumem riscos econômicos ligados à sua atividade (DEFOURNY; NYSSENS, 2008).

\section{Processo de gestão e materialização das ações do planejamento estratégico}

A gestão é caracterizada pelos processos de planejamento, execução e controle, ten- do em suas atividades aquelas que se iniciam na caracterização dos valores, da visão e da missão da organização, chegando à operacionalização e ao controle das ações de curto prazo (PEREIRA, 2011). Nesse conjunto de atividades, parte delas está focada em determinar a estratégia, operacionalizá-la e controlá-la. Essa etapa é conhecida como planejamento estratégico, que será o objeto a ser estudado nesta etapa da pesquisa.

De acordo com Porter (1989), o objetivo do planejamento estratégico consiste em criar uma posição competitiva, exclusiva, sustentável e difícil de imitar pela concorrência. Ele tem por premissa fundamental assegurar o cumprimento da missão da empresa, garantindo sua continuidade indefinidamente. Leva em conta as variáveis dos ambientes externo e interno da organização e contribui diretamente com a elaboração das diretrizes estratégicas de caráter qualitativo. Ajuda, assim, a evitar determinados riscos e a transformá-los em oportunidades.

O planejamento estratégico não deve ser entendido como um evento pontual, mas, sim, como um processo que ocorre no interior do processo de gestão. Ele pode ser compreendido a partir das seguintes 
fases: o diagnóstico estratégico, a formulação da estratégia, sua implementação e, por fim, sua avaliação e controle (TERENCE, 2011).

Dentro de cada uma dessas etapas, existem diversas atividades/processos que precisam ser realizados a fim de assegurar que a estratégia será adequadamente estabelecida, implementada e controlada (PARISI, 2011).

$\mathrm{Na}$ fase do diagnóstico estratégico, avalia-se o estágio em que a organização se encontra em relação aos ambientes externo e interno, e em que se busca identificar novas tecnologias, concorrentes potenciais, riscos conjunturais etc. Essa espécie de avaliação diagnóstica pode ser realizada com o uso de diversas ferramentas, como análise SWOT, Cadeia de Valor, Análise das 5 Forças, Matriz Produto x Mercado, Matriz BCG (PARISI, 2011).

$\mathrm{Na}$ fase de formulação da estratégia, busca-se estabelecer o conjunto de ações que assegurará o alcance da estratégia (visão), realizando sua razão de ser (missão), por meio de objetivos estratégicos que se materializam com a implementação de iniciativas estratégicas. Podem ser utilizadas nessa etapa ferramentas como: modelo de negócio Canvas (OSTEVALDER;
PIGNEUR, 2010), Balanced Scorecard (KAPLAN; NORTON, 1997, 2001, 2004), estratégia do Oceano Azul (KIM; MAUBORGNE, 2005).

$\mathrm{Na}$ fase de implementação da estratégia, são implementadas as ações (iniciativas estratégicas) definidas na fase anterior. Para os processos de implementação da estratégia, são utilizadas ferramentas como grupos de trabalhos, comitês, gestão de projetos, entre outras práticas (PARISI, 2011).

Dado o caráter recursivo do planejamento estratégico, ele é reavaliado a cada período, por meio da fase de avaliação $e$ controle da estratégia, e são realizados os ajustes que assegurem o atingimento das estratégias deliberadas e o aproveitamento das estratégias emergentes.

\section{Modelo conceitual da pesquisa}

Com base nos elementos apresentados na revisão teórica, apresenta-se o modelo com o qual será avaliado o alinhamento da organização aos indicadores de conformidade social empreendedora, a cada uma das fases do planejamento estratégico. $\mathrm{O}$ Quadro 1 representa esse modelo. 
PLANEJAMENTO ESTRATÉGICO COMO FERRAMENTA DE GESTÃO NO INSTITUTO BRASILEIRO DE GOVERNANÇA CORPORATIVA (IBGC)

\begin{tabular}{ccccc}
\hline Diagnóstico & $\begin{array}{c}\text { Formulação } \\
\text { Execução }\end{array}$ & $\begin{array}{c}\text { Avaliação e } \\
\text { da }\end{array}$ & $\begin{array}{c}\text { controle da } \\
\text { estratégia }\end{array}$ \\
\hline
\end{tabular}

\section{Dimensões econômica e empresarial das}

empresas sociais em quatro indicadores:

\begin{tabular}{lllll}
\hline $\begin{array}{l}\text { atividade contínua que produz bens e /ou } \\
\text { serviços de venda; }\end{array}$ & DE1 & DE2 & DE3 & DE4 \\
\hline alto grau de autonomia; & DE5 & DE6 & DE7 & DE8 \\
\hline nível significativo de risco econômico; & DE9 & DE10 & DE11 & DE12 \\
\hline quantidade mínima de trabalho remunerado. & DE13 & DE14 & DE15 & DE16 \\
\hline
\end{tabular}

Dimensões sociais de tais

empreendimentos das empresas sociais

em cinco indicadores:

\begin{tabular}{|c|c|c|c|c|}
\hline $\begin{array}{l}\text { objetivo explícito para beneficiar a } \\
\text { comunidade; }\end{array}$ & DS1 & DS2 & DS3 & DS4 \\
\hline iniciativa lançada por um grupo de cidadãos; & DS5 & DS6 & DS7 & DS8 \\
\hline $\begin{array}{l}\text { poder de decisão não baseado na } \\
\text { propriedade do capital; }\end{array}$ & DS9 & DS10 & DS11 & DS12 \\
\hline $\begin{array}{l}\text { natureza participativa, que envolve várias } \\
\text { partes afetadas pela atividade; }\end{array}$ & DS13 & DS14 & DS15 & DS16 \\
\hline distribuição de lucros limitada. & DS17 & DS18 & DS19 & DS20 \\
\hline
\end{tabular}

DS $=$ dimensões sociais e $\mathrm{DE}=$ dimensões econômicas.

QUADRO 1 - Modelo conceitual da pesquisa

Fonte: Elaborado pelos autores.

Compreende-se que a identificação por meios empíricos de ações em cada um dos cruzamentos (indicadores de conformidade social versus fases do planejamento estratégico) pode indicar que uma organização é uma organização social empreendedora. A inexistência ou inadequação de parte deles pode significar oportunidades de melhoria.

\section{METODOLOGIA}

Pode-se caracterizar esta pesquisa como aplicada, pois ela se concentra "em torno 
dos problemas presentes nas atividades das instituições, organizações, grupos ou atores sociais. Está empenhada na elaboração de diagnósticos, identificação de problemas e busca de soluções" (FLEURY; WERLANG, 2017, p. 2).

O procedimento para obtenção dos dados pode ser caracterizado como documental, uma vez que foram avaliados relatórios anuais emitidos pelo próprio IBGC no período de 2004 a 2016, além do website e do livro Uma década de governança corporativa (INSTITUTO BRASILEIRO DE GOVERNANÇA CORPORATIVA, 2006), que retrata detalhadamente a história do IBGC em seus primeiros dez anos de existência. Segundo Silva e Grigolo (2002), a pesquisa documental vale-se de materiais que ainda não receberam investigações aprofundadas, e, dessa forma, o material avaliado precisa ser cuidadosamente organizado, classificado e interpretado.

Para tanto, adotou-se, nesta pesquisa, a análise de conteúdo, conforme proposto por Bardin (2009), compreendendo as etapas de pré-análise, categorização, codificação e inferência.

$\mathrm{Na}$ fase de pré-analise, os relatórios foram lidos a fim de identificar os tipos de informações produzidos e como elas poderiam ser utilizadas em face do proposto nesta pesquisa. Em seguida, as evidências textuais foram categorizadas com base no modelo conceitual da pesquisa. Na próxima etapa, foram definidos os critérios que deveriam ser utilizados para considerar que uma informação existente poderia, ou não, ser considerada como associada aos elementos do modelo teórico de pesquisa. Por fim, após a análise dos elementos capturados por meio do modelo conceitual a partir dos elementos trazidos da análise documental, fez-se a inferência sobre a condição de considerar o alinhamento de uma organização com os principais indicadores de conformidade empreendedora.

Como regra para a avaliação da empresa como uma organização social empreendedora, considerou-se que ela deveria ter, em pelo menos $80 \%$ dos entroncamentos do modelo conceitual, atividades concretas realizadas, mesmo que elas necessitassem de melhorias, pois entendeu-se, com base na revisão da literatura, que o processo de melhoria é contínuo, e a busca da excelência é uma meta inalcançável. 


\section{RESULTADOS OBTIDOS E ANÁLISES}

A seguir, serão apresentadas informações sobre a organização objeto de estudo e as evidências obtidas que permitem avaliar o seu alinhamento com o modelo conceitual sintetizado no Quadro 1. Cada elemento identificado está associado a um elemento da dimensão econômica ou da social, com base no estágio do planejamento estratégico ao qual esteja associado.

Salienta-se que todo o conteúdo deste tópico foi obtido por meio dos relatórios anuais do IBGC (de 2004 a 2018), do website e do livro Uma década de governança corporativa.

\section{Caracterização da organização e seu alinhamento ao modelo conceitual}

Em 1995, Bengt Hallqvist e João Bosco Lodi, empresários e conselheiros de administração de grandes empresas internacionais, começaram a formular questões sobre a governança nas organizações e a aglutinar pessoas em torno da ideia de uma entidade que viesse a reunir conselheiros de administração, com foco idealista, não comercial (essa iniciativa pode compor as dimensões DS5 e DS6 do Quadro 1). Experientes membros de conselhos de grandes empresas, Hallqvist e Lodi inspiravam-se nos movimentos de acionistas dos Estados Unidos e da Europa em busca de novas regras que os protegessem dos abusos da presidência, da diretoria, da inércia de conselhos inoperantes e das omissões das auditorias externas (conforme modelo proposto, essa iniciativa é parte das dimensões DS1 e DS2 do Quadro 1).

Idealizado por Bengt Hallqvist e João Bosco Lodi e contando com a participação de 34 membros de áreas e empresas diversas, o IBGC foi fundado em 27 de novembro de 1995 como Instituto Brasileiro de Conselheiros de Administração (IBCA), mais tarde, em 1999, rebatizado com o nome de Instituto Brasileiro de Governança Corporativa - IBGC (é possível enquadrar essa iniciativa como parte da dimensão DS7 do Quadro 1).

Após 23 anos de sua criação, o IBGC, que é uma organização sem fins lucrativos de atuação nacional e internacional, expandiu seu objetivo de buscar a excelência na geração e disseminação de conhecimento em governança corporativa, bem como exercer papel representativo e influente na sociedade. 
Para disseminar a governança corporativa, o IBGC realiza as seguintes atividades:

- Eventos;

- Programas de treinamento nacional e jornada técnica para outros países;

- Pesquisas e publicações;

- Certificação de conselheiros;

- Vocalização e influência.

Para realizar suas atividades e manter sua independência financeira, conta com recursos provenientes das anuidades de associações (pessoa física, jurídica e mantenedores), certificações de conselheiros de administração e fiscais, inscrições nos cursos e eventos (com foco no curso para conselheiros de administração, que representa $60 \%$ de sua receita anual), bem como de patrocínios diversos (essas iniciativas compõem as dimensões DE3, DE7 e DE11 do Quadro 1).

Com sede em São Paulo, o IBGC também atua regionalmente por meio de sete capitais no país: Ceará, Minas Gerais, Paraná, Pernambuco, Rio Grande do Sul, Rio de Janeiro e Santa Catarina. Além disso, por meio de cursos in-company e eventos, atua em todos os estados brasileiros e em eventos fora do país. Também tem representatividade em institutos de gover- nança fora do país, como Global Network of Director Institutes (GNDI) e Institutos de Gobierno Corporativo de Latino América (IGCLA). O IBGC conta com o auxílio de parceiros e mais de 1.900 associados que, por meio de trabalhos voluntários, disseminam a governança por meio de palestras e produção de documentos sobre o tema (é possível alocar essa iniciativa nas dimensões DE15, DS3, DS7 e DS15 do Quadro 1).

Em 2018, a estrutura organizacional e administrativa do IBGC era composta por 57 funcionários em regime da Consolidação das Leis do Trabalho (CLT), dez estagiários e seis terceirizados. Além dos funcionários, que são remunerados, o IBGC conta, desde sua fundação, com um conselho de administração composto por nove associados pro bono, eleitos em assembleia geral e que são considerados guardiões das boas práticas de governança e responsáveis pela orientação geral, pela definição da estratégia e pelo monitoramento dos planos de ação, além de serem porta-vozes e manifestarem sobre o desenvolvimento da governança corporativa no país (conforme modelo proposto, essa iniciativa pode ser parte das dimensões DS11 e DS19 do Quadro 1). 
Apesar da promulgação da Lei nistração, apenas os funcionários CLT n. 12.868/2013, que alterou não apenas a poderão receber bonificação equivalente a Lei n. 9.532/97, mas também a chamada Lei da Filantropia (Lei n. 12.101/2009), segundo a qual os dirigentes já podem ser remunerados, sem prejuízo de benefícios tributários, o IBGC, desde a sua fundação, tem mantido seus administradores (conselheiros e diretores) não remunerados (essa iniciativa compõe as dimensões DS9 e DS17 do Quadro 1). Além disso, a política de remuneração variável do instituto determina que, mediante o atendimento de meum número predeterminado de salários de acordo com a função. O limite máximo de bonificação anual que um funcionário pode receber é de três vezes o seu salário (conforme modelo proposto, essa iniciativa pode ser parte das dimensões DS10 e DS18 do Quadro 1).

A Figura 1 contida no relatório anual 2016 demonstra a atual cadeia de valor do instituto que está focada em gerar e gerir conhecimento, disseminar conteúdo e intas pré-aprovadas pelo conselho de admi- fluenciar e representar.

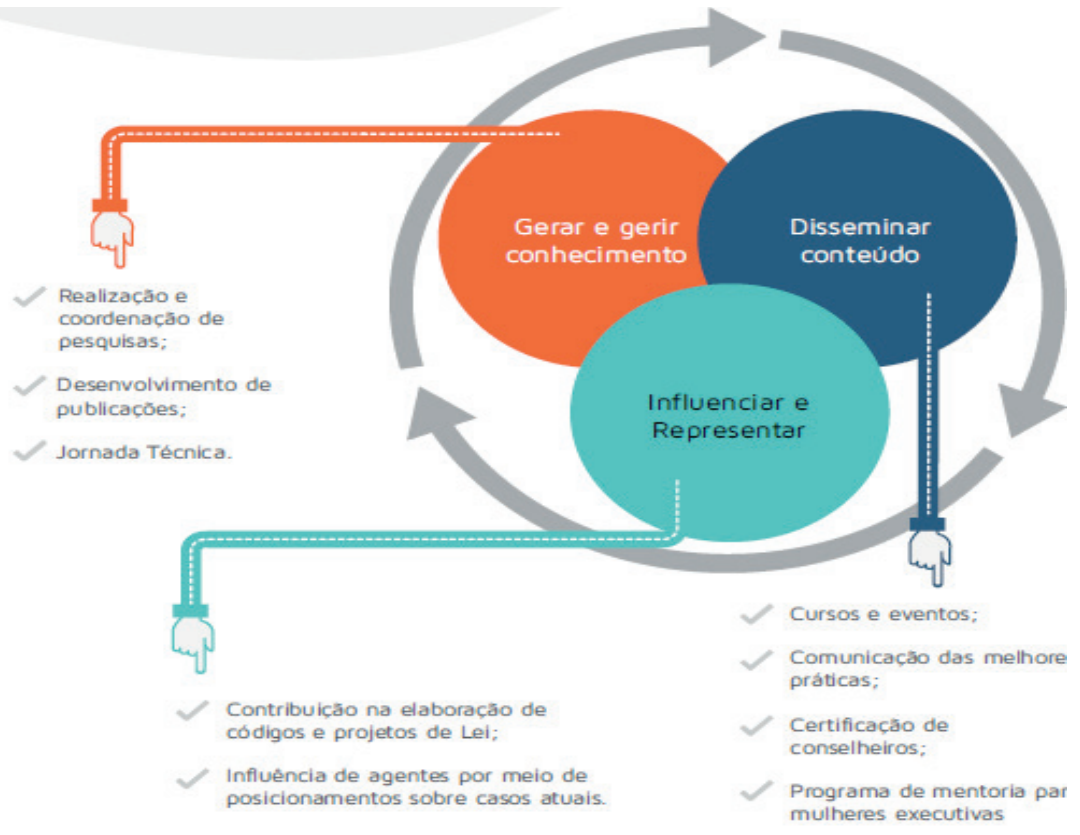

Figura 1 - Cadeia de valor do IBGC

Fonte: Relatório anual 2016. 
Em sua essência, o IBGC sempre considerou a estratégia como base para uma boa organização, principalmente porque leva em conta em seu código uma boa prática de governança corporativa. Desde sua criação, o pensamento estratégico permeou as discussões, todavia o IBGC pode ser dividido em duas fases: antes do planejamento estratégico (de 1995 a 2002) e pós-planejamento estratégico (de 2003 até os dias atuais), conforme a seguinte distribuição:

- De 1995 a 2002: antes do planejamento estratégico.

- De 2003 a 2010: primeiro planejamento estratégico.

- De 2007 a 2016: revisão do planejamento estratégico.

- De 2012 a 2016: revisão do planejamento e inclusão do Balanced Scorecard.

- De 2017 a 2020: revisão profunda do planejamento estratégico.

Após a superação inicial de introdução, legitimação e consolidação do tema governança corporativa no país em seus primeiros anos de existência, um novo desafio surgiu, que foi pensar no futuro do IBGC e na implantação do primeiro planejamento estratégico, considerado por seus conselheiros e associados ponto de vital importância para o crescimento organizado do instituto. Sintetizado no Plano Vision, o planejamento estratégico seria, a partir de então, o símbolo da linha permanente de renovação e continuidade.

Em todos os seus planejamentos estratégicos demonstrados anteriormente, o IBGC sempre contou com a participação de seus associados, conselheiros, funcionários e grupos de interesses. Desde o seu primeiro planejamento (de 2003 a 2010), já foi definido que o instituto seria consolidado patrimonialmente em situação financeira e política que lhe permitisse ser independente e implementar as ações para atingir os seus objetivos estratégicos com os investimentos necessários. Essa estratégia tem sido de sucesso, pois, conforme dados financeiros, o IBGC tem apresentado superávit em todos os seus anos (conforme modelo proposto, essa iniciativa pode ser parte das dimensões DE5 e DE6 do Quadro 1).

Desde o seu primeiro planejamento, também ficou definido e implantado um centro de pesquisa que funciona como um órgão de estudos e desenvolvimento de ideias, suprindo seus associados e o mercado com seus resultados e publicação 
de teses, monografias, estudos e livros (conforme modelo proposto, essa iniciativa pode ser parte da dimensão DS2 do Quadro 1). Grande parte desses estudos é disseminada gratuitamente por meio de publicações que podem ser adquiridas no site e nos eventos que são realizados frequentemente (conforme modelo proposto, essa iniciativa pode ser enquadrada na dimensão DS3 do Quadro 1).

O IBGC promove fóruns de debates em parcerias com entidades como Organização dos Advogados do Brasil (OAB), Bolsa de Valores de São Paulo (Bovespa), Instituto dos Auditores Independentes do Brasil (Ibracon), Comissão de Valores Mobiliários (CVM), auditorias, escritórios de advocacia, recrutadores de executivos e conselheiros, consultores, universidades e outras entidades. Promove intercâmbio e troca de experiências com organizações congêneres nacionais e internacionais. Tem participação extremamente atuante na comunidade, especialmente sendo proativo com órgãos reguladores - Executivo e Legislativo (conforme modelo proposto, essa iniciativa pode ser parte das dimensões DS14 e DS15 do Quadro 1).

Contando com a atuação pro bono da empresa Strategy\&, subsidiária da $\mathrm{PwC}$, o
IBGC realizou em 2016 uma revisão profunda de seu planejamento estratégico. Para isso, foi feita uma consulta abrangente sobre a sua atuação a todos os seus stakeholders (fundadores, gestores, funcionários, conselheiros de administração, associados, reguladores, mídia, academia, entidades congêneres nacionais e internacionais, "usuários" e ex-associados) (conforme modelo proposto, essa iniciativa pode ser parte da dimensão DS13 do Quadro 1).

O IBGC sempre utilizou metodologias consagradas para seu planejamento e formulação estratégica, como a metodologia Vision, termo inglês que significa visão, que começou aparecer nas décadas de 1980 e 1990, o Canvas e o Balanced Scorecard. Também utilizou metodologia da Strategy\&, subsidiária da PwC.

Em fevereiro de 2012, o conselho de administração aprovou o Mapa Estratégico do IBGC na linguagem Balanced Scorecard, bem como os respectivos indicadores e metas para cada perspectiva. A partir do propósito do instituto, foram estabelecidas as quatro perspectivas partindo do aprendizado, passando pela interna, pela financeira até atingir as partes interessadas. Os resultados do Mapa Estratégico e dos res- 
pectivos indicadores seguem na Figura 2 (é possível enquadrar essa iniciativa nas dimensões DE2, DE5, DS2, DS10 e DS14 do Quadro 1).

Em 2012, o conselho de administração também estabeleceu um calendário para o planejamento estratégico do IBGC, adotando a realização de uma revisão anual e ajustando os caminhos e a velocidade das ações, sem alterar o seu norte (conforme modelo proposto, essa iniciativa pode ser parte das dimensões DE4, DE8, DE12, DE16, DS4, DS8, DS12, DS16 e DS20 do Quadro 1).

Uma avaliação profunda das diretrizes estratégicas passou a ser realizada a cada quatro anos (conforme modelo proposto, essa iniciativa pode ser parte das dimensões DE1, DE5, DE9 e DS13 do Quadro 1).

Propdsito: Ser referencia em governança corporativa, contribuindo para o desempenho sustentáwel das organizazōes e influenciando os agentes de nossa sociedade no sentido de maior transparência, justiça e responsabilidade.

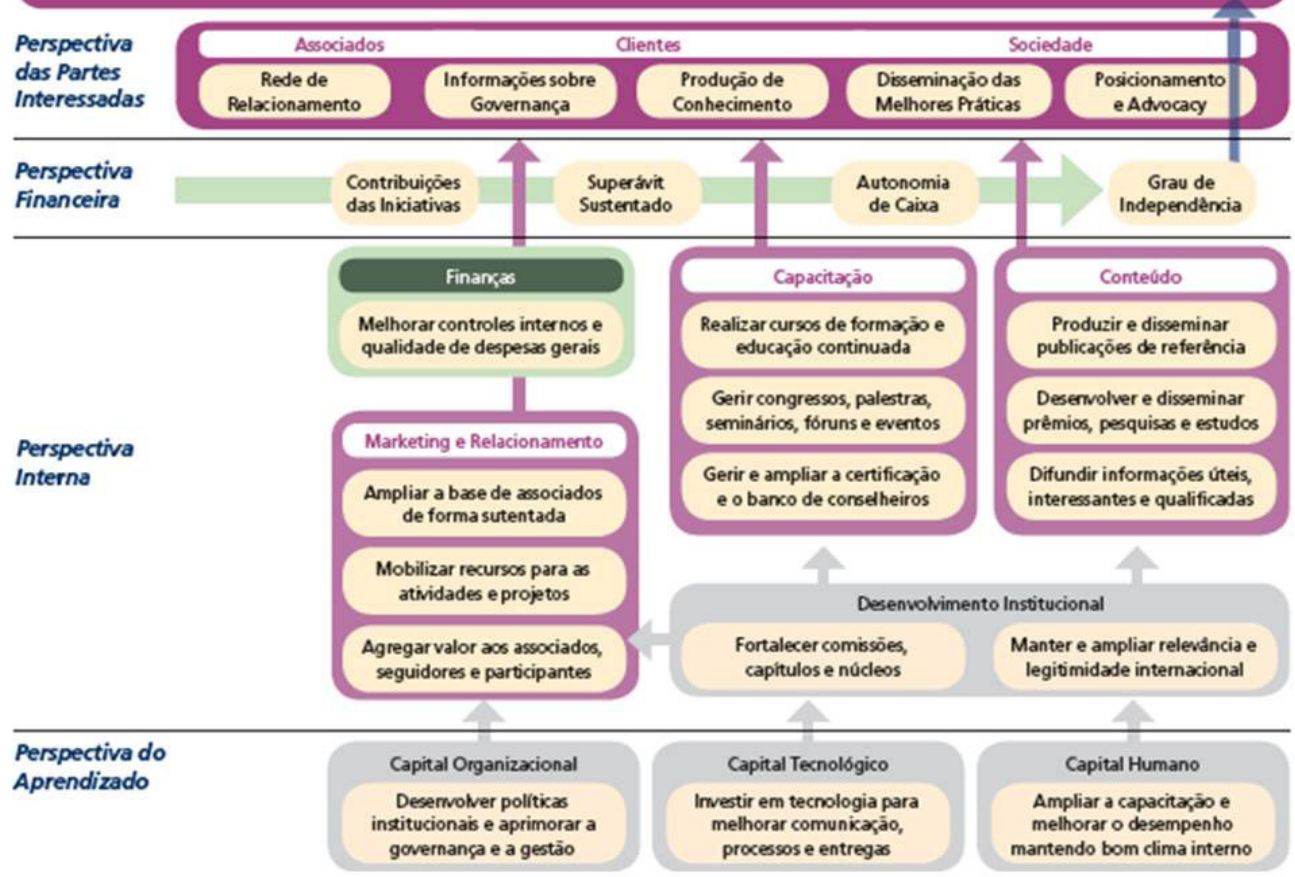

FIGURA 2 - Balanced Scorecard do IBGC: de 2012 a 2016

Fonte: Relatório anual do IBGC de 2011. 
Devido ao aumento contínuo de atividades, como cursos e eventos que demandavam a locação de espaços constantemente, em maio de 2017, o IBGC mudou para um espaço mais amplo e moderno. Isso foi possível após anos de superávit e um plano de viabilidade econômica e financeira que evidenciou a sustentabilidade do projeto. Todavia, essa mudança aumentou suas despesas fixas, uma vez que os valores de aluguel e condomínio e o aumento do quadro de funcionários foram necessários, ou seja, seu risco econômico fica evidenciado, pois, em caso de queda nas vendas dos cursos (sua maior fonte de receita), poderá haver risco da não capacidade de arcar com suas despesas fixas (conforme modelo proposto, essa iniciativa faz parte das dimensões DE9, DE10 e DE11 do Quadro 1). O tema gestão de riscos é monitorado pelo conselho e avaliado a cada semestre pelo comitê de auditoria e riscos (essa iniciativa faz parte das dimensões DE8 e DE12 do Quadro 1). Os principais riscos identificados são: crise macroeconômica; concentração e dependência de receitas; perda de eficiência operacional; perda de recursos humanos; perda de relevância do tema governança corporativa; abalos de reputação e imagem. O IBGC conta com um plano de gerenciamento de crise, que determina um responsável para cada risco, que deverá acompanhar o assunto, e uma equipe de gestão de crise, que deve ser acionada em casos de ocorrência de algum dos riscos (essas iniciativas compõem as dimensões DE9, DE10 e DE12 do Quadro 1).

\section{Síntese das evidências identificadas}

O Quadro 2 apresenta a síntese das evidências obtidas por meio da análise de conteúdo dos documentos previamente citados. Em cada entroncamento ao lado das siglas, indica-se a quantidade de vezes que práticas associadas foram identificadas no texto. Pode-se verificar que somente para o entroncamento DE14 não foram identificadas ações nos documentos analisados. Em diversos entroncamentos, identificou-se mais de uma ação, caracterizando assim um processo contínuo, ao longo das dimensões sociais e econômicas, e ao longo de todo o processo do planejamento estratégico. 


\begin{tabular}{|c|c|c|c|c|}
\hline & $\begin{array}{l}\text { Diagnóstico } \\
\text { estratégico }\end{array}$ & $\begin{array}{l}\text { Formulação } \\
\text { da } \\
\text { estratégia }\end{array}$ & $\begin{array}{l}\text { Execução } \\
\text { da } \\
\text { estratégia }\end{array}$ & $\begin{array}{l}\text { Avaliação e } \\
\text { controle da } \\
\text { estratégia }\end{array}$ \\
\hline \multicolumn{5}{|l|}{$\begin{array}{l}\text { Dimensões econômica e empresarial das } \\
\text { empresas sociais em quatro indicadores: }\end{array}$} \\
\hline $\begin{array}{l}\text { atividade contínua que produz bens e/ou } \\
\text { serviços de venda; }\end{array}$ & DE1 - 1 & DE2 - 1 & DE3 - 2 & DE4 - 1 \\
\hline alto grau de autonomia; & DE5 - 3 & DE6 - 1 & DE7 - 1 & DE8 - 2 \\
\hline nível significativo de risco econômico; & DE9 - 2 & DE10 - 2 & DE11 - 2 & DE12 - 3 \\
\hline quantidade mínima de trabalho remunerado. & DE13 - 1 & DE14 & DE15 - 1 & DE16 - 1 \\
\hline \multicolumn{5}{|l|}{$\begin{array}{l}\text { Dimensões sociais de tais } \\
\text { empreendimentos das empresas sociais em } \\
\text { cinco indicadores: }\end{array}$} \\
\hline $\begin{array}{l}\text { objetivo explícito para beneficiar a } \\
\text { comunidade; }\end{array}$ & DS1 - 1 & DS2 - 3 & DS3 - 1 & DS4 - 1 \\
\hline iniciativa lançada por um grupo de cidadãos; & DS5- 1 & DS6 - 1 & DS7 - 2 & DS8 - 1 \\
\hline $\begin{array}{l}\text { poder de decisão não baseado na } \\
\text { propriedade do capital; }\end{array}$ & DS9 - 1 & DS10 - 2 & DS11 - 1 & DS12 - 1 \\
\hline $\begin{array}{l}\text { natureza participativa, que envolve várias } \\
\text { partes afetadas pela atividade; }\end{array}$ & DS13 - 1 & DS14 - 2 & DS15- 2 & DS16 - 1 \\
\hline distribuição de lucros limitada. & DS17 - 1 & DS18 - 1 & DS19 - 1 & DS20 - 1 \\
\hline
\end{tabular}

DS = dimensões sociais e $\mathrm{DE}=$ dimensões econômicas.

QUADRO 2 - Evidências identificadas nos documentos associadas ao modelo conceitual da pesquisa Fonte: Elaborado pelos autores.

\section{CONCLUSÕES E CONSIDERAÇÕES} FINAIS

Esta pesquisa aplicada teve como objetivo principal a proposição e aplicação empírica de um modelo que possibilita avaliar se uma empresa está ou não alinhada com os principais indicadores de conformidade social empreendedor, com base nos indicadores de conformidade social propostos pelo EMES ao longo de seu processo de gestão (planejar, executar, controlar).

A empresa objeto da pesquisa foi o IBGC, delimitando-se a avaliação por 
meio da investigação do seu direcionamento estratégico no período de 1995 a 2018, a partir de evidências obtidas por meio dos relatórios anuais (de 2004 a 2018) e do livro Uma década de governança corporativa.

Com base no modelo conceitual proposto e nas evidências obtidas, pode-se considerar que o IBGC está alinhado com os principais indicadores de conformidade social empreendedora do EMES. Foi possível localizar atividades concretas inseridas em quase $100 \%$ dos entroncamentos do modelo conceitual, além de ações contínuas de melhoria que estão refletidas em seus resultados positivos e em sua expansão. Dados os resultados obtidos, considera-se que o modelo conceitual apresentado pode ser utilizado para avaliar o alinhamento das organizações aos principais indicadores de conformidade empreendedora.

Sugerem-se as seguintes pesquisas: 1. identificar o nível de alinhamento entre as diferentes áreas e cargos; e 2. replicar e expandir a pesquisa para outras instituições a fim de validar o modelo proposto.

\section{STRATEGIC PLANNING AS A MANAGEMENT TOOL AT THE BRAZILIAN INSTITUTE OF CORPORATE GOVERNANCE (IBGC)}

\section{ABSTRACT}

This applied research had as main objective to develop and to apply a alignment evaluation model for companies using the main social conformity indicators proposed by the EMES in each stage of strategic planning process. The Instituto Brasileiro de Govenança Corporativa (IBGC) was the locus of evaluation for the conceptual model based on evidences obtained from IBGC's public documents. The results suggest that IBGC demonstrates to be in line with the conceptual model proposed, in other words, it is aligned with the main entrepreneurial social conformity indicators. It was possible to locate concrete activities at almost $100 \%$ of the conceptual model junctions, in addition to the search for continuous improvement in each strategic planning's review, which has been reflected through positive results and in its expansion.

\section{KEYWORDS}

Social compliance. Strategic planning. Balanced Scorecard. Management tool. IBGC. 


\section{REFERÊNCIAS}

BERGER, P.; LUCKMANN, T. A construção social da realidade. Petrópolis: Vozes, 1998.

DEFOURNY, J.; NYSSENS, M. Conceptions of social entreprises in Europe and the United States: convergences and divergences. Leuven: Katholieke Universiteit Leuven, 2008.

EMES RESEARCH NETWORK. Disponível em: https://emes.net/who-we-are/board-of-directors/. Acesso em: 7 jun. 2019.

FLEURY, M. T. L.; WERLANG, S. R. D. C. Sessão I - Rigor metodológico nas diversas áreas de conhecimento. 2017.

INSTITUTO BRASILEIRO DE GOVERNANÇA CORPORATIVA. Uma década de governança corporativa: história do IBGC, marcos da governança e lições da experiência. São Paulo: Saint Paul, Saraiva, 2006.

INSTITUTO BRASILEIRO DE GOVERNANÇA CORPORATIVA. O papel do conselho de administração na estratégia das organizações. IBGC orienta. Livro Digital, 2017. Disponível em: https://conhecimento.ibgc.org.br/Paginas/Publicacao.aspx?PubId=23484. Acesso em: 7 jun. 2018.
INSTITUTO BRASILEIRO DE GOVERNANÇA CORPORATIVA. Disponível em: www.ibgc.org.br. Acesso em: 7 jun. 2019.

INSTITUTO BRASILEIRO DE GOVERNANÇA CORPORATIVA. Relatórios anuais de 2004 a 2018. Disponível em: http://www.ibgc.org.br/index.php/ibgc/ relatorios-anuais. Acesso em: 7 jun. 2018. KAPLAN, R. S.; NORTON, D. P. A estratégia em ação: Balanced Scorecard. Gulf Professional Publishing, 1997.

KIM, W. C.; MAUBORGNE, R. A estratégia oceano azul: como criar mais mercado e tornar a concorrência irrelevante. Rio de Janeiro: Campus, 2007.

PARISI, C. Planejamento e controle. In: PARISI, C.; MEGLIORINI, E. Contabilidade gerencial. São Paulo: Atlas, 2011. PEREIRA, C. A. Gestão econômica. In: PARISI, C.; MEGLIORINI, E. Contabilidade gerencial. São Paulo: Atlas, 2011.

PORTER, M. E. From competitive advantage to corporate strategy. In: $\mathrm{ASCH}, \mathrm{D}$; BOWMAN, C. (ed.). Readings in strategic management. London: Palgrave, 1989. p. 234-255.

SCHUMPETER, J. O fenômeno fundamental do desenvolvimento econômico. In: SCHUMPETER, J. A teoria do desenvol- 
vimento econômico. Rio de Janeiro: Nova Cultural, 1985.

SILVA, M. B. D.; GRIGOLO, T. M. Metodologia para iniciação científica à prática da pesquisa e da extensão II. Caderno Pedagógico. Florianópolis: Udesc, 2002. TERENCE, A. C. F. Planejamento estratégico como ferramenta de competitividade na pequena empresa: desenvolvimento e avaliação de um roteiro prático para o processo de elaboração do planejamento. 2002. Dissertação (Mestrado em Engenharia de Produção) - Universidade de São Paulo, São Carlos, 2002. 